\title{
ĐỊNH HƯớNG TĂNG CƯờnG CÔNG TÁC ĐÀO TẠO CÁC NGÀNH, CHUYÊN NGÀNH TRONG LĨNH VỰC MÔI TRƯỜNG ĐÁP ÚNG YÊU CẦU ĐẨY MẠNH CỔNG NGHIỆP HÓA, HIỆN ĐẠI HÓA VÀ HỘI NHẬP QUỐC TẾ
}

\author{
Nguyễn Mạnh Khải ${ }^{*}$, Hoàng Anh Lề ${ }^{1}$
}

Tóm tắt: Nhân lực là yếu tố cốt lõi, hết sức quan trọng cho sụ phát triển của các quốc gia. Trong lĩnh vưc bảo vệ và cải thiện chất lương môi truờng, không thể không quan tâm đến việc đào tạo, bồi dữ̛ng và nâng cao năng lụcc, chất luợng, phẩm chất nguồn lực con nguời. Để đáp ứng được nhu cầu và sư phát triển của xã hội, các cơ sở đào tạo cần có nhũng định hướng, kế hoạch cái tiến chất lương đào tạo nguồn nhân lục đúng đắn cho nhiệm vụ then chốt này. Chính vì vậy, bài báo này trình bày về nhũng định hướng co bản trong việc tăng cuờng công tác đào tạo các ngành, chuyên ngành trong lĩnh vục Môi truờng đáp ứng yêu cầu đẩy mạnh công nghiệp hóa, hiện đại hóa và hội nhập quốc tế.

Từ khóa: Nguồn nhân lực, Giáo dục đào tạo, Môi trường, Hội nhập quốc tế.

Ban Biên tập nhận bài: 11/12/2019 Ngày phản biện xong: 12/12/2019 ～Ngày đăng: 20/12/2019

\section{Mở đầu}

Việt Nam đang đứng trước xu hướng hội nhập và toàn cầu hoá về kinh tế xã hội, đồng thời đối mặt với các vấn đề cấp bách về môi trường (ô nhiễm môi trường, suy thoái tài nguyên, biến đổi khí hậu, dịch bệnh hoành hành). Sau đổi mới (1986), với tốc độ phát triển kinh tế vào loại cao trên Thế giới, Việt Nam được xếp vào nhóm 5 quốc gia chịu ảnh hưởng mạnh mẽ của biến đổi khí hậu, có tốc độ suy thoái đa dạng sinh học cao, môi trường đất, không khí và nước ở nhiều vùng bị ô nhiễm nghiêm trọng, các loại tài nguyên thiên đang bị khai thác với mức độ ngày càng cao [7-8].

Ngày 15 tháng 11 năm 2004, Bộ Chính trị Ban chấp hành Trung ương Đảng Cộng sản Việt Nam đã ban hành Nghị quyết 41/NQ-TW về bảo vệ môi trường trong thời kỳ đẩy mạnh công nghiệp hoá và hiện đại hoá đất nước. Một trong các nhiệm vụ đặt ra trong Nghị quyết là "Tăng cường đào tạo nguồn nhân lực về môi trường. Mở rộng và nâng cao chất lượng đào tạo nhân

${ }^{1}$ Khoa Môi truòng, Truờng Đại hoc Khoa học

Tự nhiên, Đại học Quốc gia Hà Nội

Email:nguyenmanhkhai@hus.edu.vn lực, đáp ứng nhu cầu công tác bảo vệ môi trường tại trường đại học, cao đẳng và các viện nghiên cứu" [10]. Nhằm quán triệt Chỉ thị số 36-CT/TW ngày 25/6/1998 của Bộ Chính trị [6], Quyết định số 1363/QĐ-TTg ngày 17/10/2001 của Thủ tướng Chính phủ [2], Quyết định số 256/2003/QĐ-TTg ngày 02/12/2003 của Thủ tướng Chính phủ [3] và Nghị quyết số 41NQ/TW ngày 15/11/2004 của Bộ Chính trị, ngày 31/01/2005 [10], Bộ trưởng Bộ Giáo dục và Đào tạo đã ban hành Chỉ thị "Tăng cường công tác giáo dục bảo vệ môi trường" [4]. Trong các nhiệm vụ được đề cập trong văn bản này có nhiệm vụ: “.. đào tạo cán bộ chuyên môn, cán bộ quản lý ở trình độ trung học chuyên nghiệp, cao đẳng, đại học và sau đại học về các chuyên ngành môi trường để từng bước đáp ứng nhu cầu nguồn nhân lực bảo vệ môi trường trong thời kỳ công nghiệp hóa, hiện đại hóa đất nước" [4].

Trong điều kiện đẩy mạnh công nghiệp hoá, hiện đại hóa và hội nhập quốc tế như hiện nay, việc phát triển nguồn nhân lực thông qua định 
hướng đào tạo được coi là một trong ba khâu đột phá của chiến lược chuyển đổi mô hình phát triển kinh tế - xã hội của đất nước. Phát triển nguồn nhân lực được xác định trở thành nền tảng phát triển bền vững và tăng lợi thế cạnh tranh quốc gia. Bài báo này đánh giá thực trạng công tác đào tạo, làm rõ một số tồn tại và đưa ra những định hướng trong đào tạo nguồn nhân lực ngành Môi trường nhằm đáp ứng yêu cầu đẩy mạnh công nghiệp hóa, hiện đại hóa và hội nhập quốc tế trong thời gian tới.

\section{Phương pháp nghiên cứu}

Trong nghiên cứu này, phương pháp nghiên cứu chủ yếu gồm (i) tổng thuật tài liệu; (ii) khảo sát đánh giá (iii) phương pháp chuyên gia. Thông tin được thu thập và tổng hợp dựa vào lịch sử hình thành, kết quả tổng kết các thành tựu về đào tạo và nghiên cứu khoa học trong lĩnh vực môi trường [1]. Ngoài ra, nguồn thông tin, số liệu được khảo cứu từ tài liệu tuyển sinh đại học, sau đại học và các thông tin được đăng tải trên website của các trường Đại học có tuyển sinh và đào tạo lĩnh vực môi trường trong cả nước. Bên cạnh đó là sự tổng hợp ý kiến của các chuyên gia, các nhà khoa học và nhìn nhận từ cương vị, kinh nghiệm quản lý của các tác giả bài báo này trong lĩnh vực đào tạo và nghiên cứu khoa học về môi trường.

\section{Kết quả và bàn luận}

\subsection{Tình hình thục trang chung}

Hiện nay, cả nước có khoảng trên 60 cơ sở đào tạo bậc đại học, cao đẳng các ngành, chuyên ngành về môi trường (Bảng 1); trong đó, có các cơ sở đào tạo có truyền thống như Đại học Quốc gia Hà Nội, Đại học Bách khoa Hà Nội, Đại học Xây dựng, Đại học Quốc gia thành phố Hồ Chí Minh,. Bên cạnh đó là các trường đại học khác như, Thủy lợi, Nông nghiệp, Mỏ - Địa chất; nhóm các đại học khu vực như Thái Nguyên, Tây Bắc, Hải Phòng, Huế, Đà Nẵng, Tây Nguyên, Cần Thơ và nhiều trường đại học địa phương trong cả nước [5]. Các ngành đào tạo về môi trường bao gồm: Kỹ thuật môi trường/Công nghệ kỹ thuật môi trường, Quản lý tài nguyên và môi trường, Khoa học môi trường. Tổng chỉ tiêu đào tạo năm 2014 khoảng 11.000 sinh viên, năm 2015 khoảng 12.500 sinh viên, năm 2018 giảm xuống còn khoảng 7.600, 2019 khoảng 7.000 [5]. Hầu hết các trường đào tạo có truyền thống đào tạo lâu năm về môi trường đảm bảo điều kiện về trình độ đội ngũ giảng viên. Nhiều đơn vị đào tạo có tỷ lệ giảng viên có trình độ sau đại học chiếm trên $70 \%$, trong khi đó những đơn vị mới mở ngành hoặc mới thành lập, tỷ lệ giảng viên đạt trình độ thạc sĩ, tiến sĩ thấp dưới 50\%.

Bảng 1. Tổng hợp thông tin các truờng Đại học và chỉ tiêu tuyển sinh

\begin{tabular}{|c|c|c|c|c|c|}
\hline TT & Đơn vị đào tạo & Ngành đào tạo & $\begin{array}{l}\text { Năm } \\
2014\end{array}$ & $\begin{array}{l}\text { Năm } \\
2015\end{array}$ & $\begin{array}{l}\text { Năm } \\
2018\end{array}$ \\
\hline $\mathbf{A}$ & $\begin{array}{l}\text { Nhóm ngành môi trường } \\
\text { khu vực phía nam }\end{array}$ & & 5.400 & 6.300 & 4.065 \\
\hline 1 & $\begin{array}{l}\text { Trường Đại học Bách } \\
\text { Khoa - ĐHQG TP.HCM }\end{array}$ & $\begin{array}{l}\text { Kĩ thuật môi trường } \\
\text { Quản lý Tài nguyên và Môi } \\
\text { trường }\end{array}$ & 160 & 170 & 100 \\
\hline \multirow{2}{*}{2} & \multirow{2}{*}{$\begin{array}{l}\text { Trường Đại học Khoa học } \\
\text { Tự nhiên - ĐHQG } \\
\text { TPHCM }\end{array}$} & $\begin{array}{l}\text { Khoa học Môi trường (Khoa học } \\
\text { Môi trường, Tài nguyên Môi } \\
\text { trường, Quản lí Môi trường, Tin } \\
\text { học Môi trường, Môi trường \& } \\
\text { Tài nguyên biển) }\end{array}$ & 175 & 215 & 50 \\
\hline & & $\begin{array}{l}\text { Công nghệ kỹ thuật môi trường } \\
\text { (Công nghệ môi trường nước và } \\
\text { đất, Công nghệ môi trường khí } \\
\text { và chất thải rắn) }\end{array}$ & 120 & 215 & 100 \\
\hline
\end{tabular}


3

Trường Đại học Tôn Đức Thắng

4 Trường Đại học Công nghiệp TP.HCM

Trường Đại học Công nghiệp Thực phẩm TP.HCM (hệ Đại học, $\mathrm{CĐ)}$

Trường Đại học Nông Lâm TP.HCM

7 Trường Đại học Sài Gòn

8

Trường Đại học Sư phạm Kỹ thuật TP.HCM

9 Trường Đại học Quốc tế Hồng Bàng (Hệ ĐH, CĐ)

10

Trường Đại học Công nghệ TP.HCM

11 Trường Đại học Dân lập Văn Lang

12 Phân hiệu Đại học Huế tại Quảng Trị

13

Trường Đại học Nông Lâm - ĐH Huế

14

Trường Đại học Khoa học - ĐH Huế

15

Trường Đại học Sư phạm

- ĐH Đà Nẵng

16 Trường Đại học Bách Khoa - ĐH Đà Nẵng

17 Đại học Đồng Nai

18 Trường Đại học Đà Lạt

19 Trường Đại học Nha Trang

20 Trường Đại học Tây Nguyên

21 Trường Đại học dân lập Yersin Đà Lạt

22 Trường Đại học An Giang

23 Trường Đại học Cần Thơ
Công nghệ kĩ thuật môi trường (chuyên ngành cấp thoát nước và môi trường)

Khoa học môi trường (Khoa học Kỹ thuật môi trường)

Công nghệ kỹ thuật môi trường Gồm 02 chuyên ngành:

- Công nghệ kỹ thuật môi trường

- Quản lý tài nguyên và môi trường

Công nghệ kỹ thuật môi trường

ĐH: $200 \quad$ ĐH: $200 \quad$ ĐH: 120

CĐ: $100 \quad$ CĐ: $80 \quad$ CĐ: -

Kỹ thuật môi trường

Quản lý tài nguyên và môi trường

Khoa học môi trường

Khoa học môi trường

Công nghệ kĩ thuật môi trường

Công nghệ kỹ thuật môi trường

Khoa học môi trường

Kỹ thuật môi trường (ĐH)

Công nghệ kỹ thuật môi trường (CĐ)

Công nghệ kĩ thuật môi trường

Công nghệ kĩ thuật môi trường

Quản lý Tài nguyên và Môi trường (Chuyên ngành Quản lý đất đai)

Khoa học môi trường

Quản lý Tài nguyên và Môi trường

Khoa học môi trường

Quản lý Tài nguyên và Môi trường

Kỹ thuật môi trường

Quản lý Tài nguyên và Môi trường

Khoa học Môi trường (CĐ)

Khoa học Môi trường

Công nghệ kỹ thuật môi trường

Công nghệ kỹ thuật môi trường

Khoa học Môi trường (gồm các chuyên ngành: Công nghệ môi trường, Quản lý môi trường)

Công nghệ kĩ thuật môi trường

Quản lý Tài nguyên và Môi trường

Khoa học môi trường

Kĩ thuật môi trường

Quản lý tài nguyên và môi trường

80

120

40

100

120

50

ĐH: 350

$\mathrm{CĐ:} 100$

$\begin{array}{ccc}110 & 110 & 110 \\ 160 & 160 & 160 \\ \text { Chưa có } & 80 & 80 \\ 70 & 70 & 100 \\ 60 & 70 & 70 \\ & 120(30 & 120 \\ 80 & \text { CLC, } & \text { (60 CLC, } \\ & 90 \text { Đại } & 60 \text { Đại } \\ & \text { trà) } & \text { trà) } \\ \text { ĐH: } 70 & \text { ĐH: } 200 & \text { ĐH: } 50 \\ \text { CĐ: } 70 & \text { CĐ: } 80 & \text { CĐ: Bỏ } \\ 200 & 200 & 150 \\ 100 & 60 & - \\ & & \\ 140 & 120 & 60 \\ \text { ĐH: } 50 & \text { ĐH: } 50 & \text { ĐH: } 40 \\ \text { CĐ: } 50 & \text { CĐ: } 51 & \text { CĐ: N/A }\end{array}$

$\begin{array}{ccc}200 & 250 & 100 \\ 70 & 70 & 60 \\ 60 & 70 & 70 \\ 65 & 70 & 85 \\ 65 & 65 & 60 \\ 60 & 70 & 60 \\ 60 & 60 & 60 \\ 50 & 50 & - \\ 90 & 110 & 100 \\ \text { Đ: } 100 & Đ H: 100 & \text { Đ: } 40 \\ \text { CĐ: } 50 & \text { CĐ: } 50 & \text { СĐ:- } \\ 80 & 90 & 50 \\ & & \\ 60 & 60 & 20 \\ 50 & 50 & 30 \\ 100 & 100 & 30 \\ 120 & 120 & 140 \\ 120 & 120 & 130 \\ 100 & 80 & 100 \\ & & \end{array}$


33 Trường Đại học Nguyễn Tất Thành Trường Đại học Dân lập Lạc Hồng

Nhóm ngành môi trường khu vực phía bắc

Trường ĐH Khoa học Tự

1 nhiên (ĐHQG Hà Nội)

2 Trường Đại học Bách khoa Hà Nội

3 Trường Đại học Giao thông vận tải

4 Trường Đại học Kiến trúc

4 Hà Nội

5 Trường Đại học Lâm nghiệp

6 Học viện Nông nghiệp Việt Nam
Kỹ thuật môi trường

Quản lý tài nguyên và môi trường

Khoa học môi trường

Công nghệ kĩ thuật môi trường

Khoa học môi trường

Quản lý tài nguyên và môi trường

Công nghệ kĩ thuật môi trường

Công nghệ kĩ thuật môi trường

Quản lý TN và MT

Công nghệ kĩ thuật môi trường

Quản lý $\mathrm{TN}$ và $\mathrm{MT}$

Công nghệ kĩ thuật môi trường

Quản lý Tài nguyên và Môi

trường

Quản lý Tài nguyên và Môi trường

Khoa học môi trường

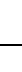

(20)

Khoa học đất

Khoa học môi trường

Công nghệ kĩ thuật môi trường Quản lý $\mathrm{TN}$ và $\mathrm{MT}$

Kỹ thuật môi trường

Kỹ thuật môi trường

Kỹ thuật đô thị (có chuyên ngành

Kỹ thuật môi trường đô thị)

Khoa học môi trường

Quản lý TN \& MT

Khoa học môi trường (Hệ $\mathrm{CĐ)}$

Khoa học Môi trường (chuyên ngành: Môi trường, Quản lí Môi trường, Công nghệ Môi trường)

Công nghệ kĩ thuật môi trường (CĐ)

Công nghệ kỹ thuật môi trường (ĐH)

$\begin{array}{ccc}150 & 180 & 50 \\ 70 & 100 & 40 \\ \text { ĐH: } 190 & \text { ĐH: } 244 & \text { ĐH: } 210 \\ \text { CĐ: } 80 & \text { CĐ: } 50 & \text { CĐ: - } \\ 150 & 150 & 150 \\ 100 & 150 & 100 \\ 50 & 50 & -\end{array}$

ĐH: 150 ĐH: 150

CĐ: 60 CĐ: 30

$\begin{array}{lll}60 & 60 & 80\end{array}$

ĐH: 150 ĐH: 250

CĐ: 40 CĐ: 25 ĐH: 100

\begin{tabular}{ccc}
\multicolumn{2}{c}{ Chưa có } & 200 \\
100 & 115 & 30 \\
100 & 115 & 30 \\
250 & 300 & 60 \\
114 & 114 & 50 \\
5.600 & 6.200 & 3.542 \\
\hline 50 & 40 & $\begin{array}{c}0 \\
\text { ĐT Chuẩn } \\
: 88\end{array}$ \\
80 & 80 & $\begin{array}{l}\text { CTĐT } \\
\text { Tiên tiến: } \\
40\end{array}$
\end{tabular}

$\begin{array}{ccc}60 & 60 & 79 \\ 50 & 60 & 40 \\ >110 & 144 & 120 \\ 50 & 50 & 50 \\ & & \\ 50 & 50 & 30 \\ 200 & 250 & 100 \\ 50 & 50 & 70 \\ 60 & 30 & - \\ 348 & & \\ \begin{array}{c}\text { Chia } \\ \text { dều }\end{array} & 600 & 280 \\ 25 & & \\ \text { ngành) } & & \\ 150 & & \\ \text { (Chia } & & \\ \text { dều } & 175 & -\end{array}$

ngành)

120

(Chia

đều

200

200 
Trường Đại học Tài

7 nguyên và Môi trường Hà Nội

Trường Đại học Thủy lợi

9 Trường Đại học Xây dựng

10 Trường Đại học Dân lập Đông Đô

11 Trường Đại học Dân lập Phương Đông

12 Trường Đại học Thành Đô

Trường Đại học Kỹ thuật

13 Công nghiệp (ĐH Thái Nguyên)

14

Trường Đại học Nông lâm (ĐH Thái Nguyên)

15

Trường Đại học Khoa học (ĐH Thái Nguyên)

16 Trường Đại học Công nghiệp Việt Trì

17 Trường Đại học Hồng Đức

18 Trường Đại học Sư phạm Kỹ thuật Hưng Yên

19 Trường Đại học Tây Bắc

20 Trường Đại học Vinh

21 Trường Đại học Công nghiệp Hà Nội

Trường Đại học Hà Tĩnh

22 (Đào tạo nhân lực cho Khu kinh tế Vũng Áng)

23 Trường Đại học Hàng Hải Việt Nam

24 Trường Đại học Mỏ Địa chất

25 Trường Đại học Nông lâm Bắc Giang

26 Trường Đại học Dân lập Hải Phòng
Quản lý Tài nguyên và Môi trường $(\mathrm{ÐH})$

Công nghệ kỹ thuật môi trường $(\mathrm{C} Đ)$

Công nghệ kỹ thuật môi trường (Liên thông)

Quản lý Tài nguyên và Môi trường (LT)

Kỹ thuật môi trường

Công nghệ kỹ thuật môi trường

Công nghệ kỹ thuật môi trường

Công nghệ kỹ thuật môi trường

Công nghệ kỹ thuật môi trường (ĐH)

Quản lý Tài nguyên và Môi trường $(\mathrm{ÐH})$

Công nghệ kỹ thuật môi trường (CĐ)

Quản lý Tài nguyên và Môi trường $(\mathrm{CĐ})$

Kỹ thuật môi trường

Khoa học môi trường

Khoa học và QLMT (tiên tiến)

Quản lý TN\&MT

Khoa học môi trường

Quản lý TN\&MT

Công nghệ kĩ thuật môi trường

Công nghệ kỹ thuật môi trường

Công nghệ Kĩ thuật Môi trường (gồm các chuyên ngành: CNMT, QLMT)

Quản lý tài nguyên và môi trường

Khoa học môi trường (Cử nhân) Quản lý TN\&MT (Kỹ sư)

Công nghệ kĩ thuật môi trường

Khoa học môi trường

Kĩ thuật môi trường

Kĩ thuật môi trường

Quản lý $\mathrm{TN}$ và $\mathrm{MT}(\mathrm{HH})$

Quản lý $\mathrm{TN}$ và $\mathrm{MT}(\mathrm{CĐ})$

Kĩ thuật môi trường
(Chia

đều

10

ngành)

25 (Chia đều

13

ngành)

240

50

30

30

140

250

100

100

150

130

150

60

160

140

160

140

90

$25 \quad 30$

25

30

70

60

40

230

140

110

60

100

150

70

50

70

100

30

150

60

175

180

80

80

80

30

$>190$

(chia

đều

13

ngành)

180

150

80

ĐH: 180

CĐ: 150

$$
400
$$

500

120

120

70

ĐH: 180

70

CĐ: 80 ĐH: 50

$600 \quad 400 \quad 100$

120

135

135

$250 \quad 280$

40

75

120

40

30

230
Bỏ

225
150 


\begin{tabular}{|c|c|c|c|c|c|}
\hline 27 & $\begin{array}{l}\text { Trường Đại học Nguyễn } \\
\text { Trãi }\end{array}$ & Công nghệ kĩ thuật môi trường & 25 & 127 & 75 \\
\hline 28 & Trường Đại học Tân Trào & Khoa học môi trường & 56 & 65 & 25 \\
\hline \multicolumn{3}{|c|}{ Tổng } & 11.000 & 12.500 & 7.607 \\
\hline
\end{tabular}

3.2. Thục trạng đào tạo nhân lục môi truò̀ng tại Khoa môi trưòng, Truờng Đại học Khoa họ Tư nhiên, ĐHQGHN

Từ những năm 90 của thế kỷ 20, nhận thấy tầm quan trọng về đào tạo các cán bộ môi trường có trình độ cao, các nhà khoa học thuộc Trường Đại học Tổng hợp Hà Nội đã đề xuất và được Bộ Giáo dục và Đào tạo cho phép đào tạo thí điểm nguồn nhân lực về môi trường. Trong thời gian từ 1991 - 1995 số lượng sinh viên nhập học là 58 (năm 1991) và 70 (năm 1992) và bắt đầu mở các khoá đào tạo hệ chính quy với 43 sinh viên (năm 1994) và 145 sinh viên (năm 1995) [9]. Trước yêu cầu thực tế rất lớn về đào tạo cán bộ môi trường ở Việt Nam và kết quả thử nghiệm đào tạo cán bộ môi trường tại Trường Đại học Tổng hợp Hà Nội, ngày 21 tháng 10 năm 1995, Giám đốc Đại học Quốc gia Hà Nội, GS.VS. Nguyễn Văn Đạo đã ký quyết định số 435/TCCB về việc thành lập Khoa Môi trường (KMT) thuộc Trường Đại học Khoa học Tự nhiên trên cơ sở hợp nhất các Bộ môn: Môi trường, Địa môi trường và Thổ nhưỡng (Khoa Sinh học) [9].

Kể từ ngày thành lập đến nay, KMT đã từng bước và liên tục phát triển cả về nội dung và chất lượng đào tạo chuyên sâu. Giai đoạn đầu khi mới thành lập, với đội ngũ cán bộ gồm 20 người thực hiện việc đào tạo bậc đại học và thạc sĩ ngành Môi trường, tiếp nhận và tiếp tục đào tạo bậc đại học, thạc sĩ và tiến sĩ ngành Khoa học đất; đến nay đội ngũ cán bộ của Khoa đã đạt đến 56 cán bộ, thực hiện xuyên suốt chương trình đào tạo Cử nhân, Thạc sĩ, Tiến sĩ ngành Khoa học môi trường (KHMT), Cử nhân, Thạc sĩ, Tiến sĩ ngành Khoa học đất, Cử nhân, Thạc sĩ ngành Công nghệ kỹ thuật môi trường.

Tính đến năm 2019, KMT đã đào tạo được khoảng 3000 cử nhân KHMT, Công nghệ môi trương, Khoa học đất; 1500 Thạc sĩ KHMT; 50 Tiến sì. Số cán bộ đã được đào tạo hiện đang công tác tại các cơ quan, viện nghiên cứu thuộc lĩnh vực môi trường và quản lý khác của nhà nước và các tổ chức phi chính phủ.

Ngành KHMT: Ngành KHMT hệ đại học được triển khai đào tạo liên tục từ năm 1995 đến nay. Hình thức đào tạo chủ yếu là chính quy tập trung. Từ năm 2001 đến nay, KMT được Trường giao tuyển sinh và đào tạo 1 lớp sinh viên chất lượng cao ngành KHMT (từ 15-20 sinh viên/khóa). Việc đào tạo cao học chuyên ngành KHMT được tiến hành liên tục từ năm 1993 đến nay với quy mô tương đối ổn địinh. Từ năm 2004, KMT bắt đầu tổ chức đào tạo tiến sĩ KHMT theo các hướng chuyên ngành Môi trường đất và nước - 2004, Môi trường không khí - 2004, Khoa học môi trường - 2012, Môi trường và phát triển bền vững - 2014. Đào tạo đại học và sau đại học ngành KHMT tại KMT đã và đang có vị trí và thương hiệu trong nước và quốc tế. Năm 2010, KMT được phép tuyển sinh và tổ chức đào tạo chương trình tiên tiến ngành KHMT, liên kết, hợp tác với Đại học Indiana, Hoa Kỳ với số lượng tuyển sinh hàng năm trên 30 sinh viên. Chất lượng đào tạo đại học và sau đại học ngành KHMT đã được xã hội ghi nhận và đánh giá tốt. Tuyển sinh hàng năm có quy mô tương đối ổn định: 80-120 sinh viên, 100-120 học viên cao học, 5-10 nghiên cứu sinh.

Ngành Công nghệ kỹ thuật môi trường: Ngành Công nghệ kỹ thuật môi trường được hình thành trên cơ sở chuyên ngành Công nghệ môi trường thuộc ngành KHMT năm 2004. Bậc đại học liên tục ổn định ở mức 60-80 sinh viên/khóa theo học. Năm 2013, Đại học Quốc gia Hà Nội cho phép Khoa đào tạo sau đại học bậc Thạc sĩ chuyên ngành Kỹ thuật môi trường. Hàng năm chuyên ngành này tuyển sinh với số lượng 20-30 học viên theo học. Tư năm 2018, chuyên ngành Kỹ thuật môi trường được phép $p$ tuyển sinh và đào tạo bậc Tiến sĩ. Đến nay đã có 04 NCS nhập học và thực hiện luận án Tiến sĩ tại KMT về chuyên ngành này. 
Ngành Khoa học đất (Thổ nhưỡng): Ngành đã có hơn 50 năm kinh nghiệm đào tạo, chuyển từ khoa Sinh học của Trường Đại học Tổng hợp Hà Nội sang, với 3 bậc đào tạo đại học, cao học và tiến sĩ xuyên suốt. Từ khi thành lập KMT ngành có quy mô ổn định đào tạo mỗi năm 30-40 sinh viên đến năm 2012. Tuy nhiên, đến nay Ngành Khoa học đất đang nỗ lực quảng bá để thu hút được lượng đông số người đăng ký học tập.

\subsection{Một số bất cập trong đào tạo nguồn nhân lục}

Thứ nhất: Chương trình, giáo trình đào tạo của các Trường đã được quan tâm đầu tư xây dựng, tuy nhiên việc xác định nhu cầu thị trường và thống nhất các khối kiến thức cốt lõi của ngành/chuyên ngành, xây dựng chuẩn đầu ra cho các ngành, chuyên ngành đào tạo còn chưa được chú trọng ở cấp quản lý vĩ mô. Thuật ngữ sử dụng trong ngành nhiều nơi chưa thống nhất (nặng về ngôn ngữ dịch thuật, chưa được thống nhất trong Việt hoá). Công tác biên soạn tài liệu học tập và giáo trình chưa được tạo điều kiện khuyến khích cũng như nâng cao chất lượng.

Thứ hai: Công tác đào tạo nhân lực cho ngành theo tổng kết tại Bảng trong các năm vừa qua còn nhiều bất cập, mất cân đối giữa các ngành (Quản lý tài nguyên và môi trường/ Kỹ thuật môi trường/ Khoa học môi trường/Phát triển bền vững/Biến đổi khí hậu), các cấp đào tạo (Cao đẳng/Đại học/Thạc sĩ/Tiến sĩ). Trong đó đặc biệt là bậc đào tạo đại học có xu hướng tăng cao hơn các bậc cao đẳng, thạc sĩ và tiến sĩ. Hệ thống các cơ sở đào tạo còn thiếu đồng bộ và chưa có tính liên thông, liên kết cao. Nhiều trường đại học mới mở ngành chỉ chú ý đào tạo các ngành thiên hướng về quản lý môi trường, ít chú trọng đào tạo cán bộ kỹ thuật, công nghệ môi trường ở bậc đại học.

Thứ ba: Đội ngũ cán bộ, giảng viên có trình độ chuyên môn cao trong nhiều cơ sở đào tạo còn chiếm tỷ lệ thấp. Hoặc nhiều cán bộ có trình độ chuyên môn cao, được đào tạo ở cơ sở có uy tín trong và ngoài nhưng thâm niên công tác trong lĩnh vực đào tạo lại chưa cao, kinh nghiệm thực tiễn còn tồn tại một số hạn chế. Hội nhập quốc tế trong đào tạo về lĩnh vực môi trường còn bị hạn chế bởi rào cản ngôn ngữ không chỉ của người học mà còn cả từ không ít cán bộ giảng dạy.

Thứ tư: Cơ sở vật chất, hạ tầng kỹ thuật, phòng thí nghiệm thực hành của hầu hết các cơ sở đào tạo về môi trường còn rất hạn chế, chưa đáp ứng yêu cầu về số lượng và chất lượng. Quy hoạch ngành, mạng lưới các trường đại học trong lĩnh vực môi trường chưa được triển khai hoặc chậm so với kế hoạch dẫn đến nhiều đơn vị đào tạo chưa tạo được thế ổn định và chủ động trọng định hướng phát triển của mình.

Thứ năm: Đầu tư cho nghiên cứu khoa học cho các trường Đại học về lĩnh vực môi trường còn ít và thụ động. Đội ngũ cán bộ giảng dạy về môi trường không được cấp kinh phí nghiên cứu thường niên nên ảnh hưởng ít nhiều đến chất lượng đào tạo; nghiên cứu khoa học không được gắn kết mật thiết với đào tạo đại học và sau đại học dẫn đến hệ quả có thể xảy ra tình trạng đào tạo chay, ít gắn liền với thực tiễn và nhu cầu xã hội.

Thứ sáu: Do việc quy hoạch ngành và dự báo nhân lực ngành, cơ cấu nhân lực ngành môi trường còn có những bất cập, chưa đảm bảo chặt chẽ, khoa học và đảm bảo tính chính xác. Hiện nay có nguy cơ "khủng hoảng thừa" về số lượng nhưng "khủng hoảng thiếu" về chất lượng nguồn nhân lực ngành môi trường ở trình độ đại học. Tồn tại một thực tế là một bộ phận không nhỏ người học khó xin việc làm đúng chuyên môn được đào tạo hoặc phải xin làm việc với các ngành nghề khác dẫn đến lãng phí.

\subsection{Dụ báo nhu cầu nguồn nhân lục ngành môi trường trong thời kỳ công nghiệp hóa, hiện đại hóa và hội nhập quốc tế}

Theo bảng tổng kết ở trên từ dữ liệu tuyển sinh 2014, 2015 mỗi năm khoảng 10.000 sinh viên được tuyển. Nếu tính với dữ liệu tuyển sinh này cho giai đoạn 2011-2015 tương tự như vậy trong thì đến năm 2019, tổng số nhân lực trình độ đại học được đào tạo trong giai đoạn 2011-2015 ước tính khoảng 50.000 người, tương đương với 
500 người/1 triệu dân. So sánh đội ngũ cán bộ làm công tác môi trường ở các nước như Singapore là 330 người/1 triệu dân. Đối với các nước phát triển thì con số của Việt Nam còn cao hơn nhiều, ví dụ như: Canađa là 155 người, Anh là 204 người/triệu dân (tham khảo từ JICA). Việt Nam được cho là có đội ngũ nhân lực làm môi trường cao hơn. Do đó trong thời gian tới, nhu cầu bồi dưỡng tay nghề (trình độ cao đẳng) và chuyên môn chuyên sâu (sau đại học) đối với cán bộ môi trường là cấp thiết. Việc tính toán nhu cầu và điều chỉnh số lượng/chỉ tiêu đào tạo trình độ đại học cần xem xét một cách nghiêm túc trong quy hoạch nguồn nhân lực các bậc trong ngành môi trường.

\subsection{Một số đề xuất định hướng tăng cường} công tác đào tạo các ngành, chuyên ngành trong lĩnh vục Môi truò̀ng

Qua những đánh giá, dự báo về công tác đào tạo các ngành, chuyên ngành trong lĩnh vực môi trường nói trên cũng như những nhận định dự báo nhu cầu nguồn nhân lực ngành môi trường, để đáp ứng được nhu cầu của xã hội trong thời kỳ công nghiệp hóa, hiện đại hóa và hội nhập quốc tế; Một số giải pháp mang tính định hướng được đề xuất như sau:

- Khảo sát, đánh giá nhu cầu thị trường lao động một cách liên tục, xác định/định hình được chuẩn đầu ra của ngành/ chuyên ngành về kiến thức, kỹ năng, thái độ, năng lực... đảm bảo đáp ứng được nhu cầu xã hội nhưng phù hợp với đặc thù của cơ sở đào tạo.

- Cần có quy hoạch nguồn nhân lực ngành/chuyên ngành môi trường và định hướng đào tạo ngành trong từng giai đoạn, nhất là giai đoạn 2020-2030. Quy hoạch mạng lưới, phân tầng chất lượng các trường đại học, cao đẳng trong lĩnh vực môi trường.

- Tăng cường năng lực nghiên cứu khoa học và đào tạo chất lượng cao, gắn với yêu cầu thực tiễn cho các cơ sở giáo dục đào tạo nhân lực môi trường (trang thiết bị, cơ sở vật chất, đề tài dự án; liên kết với doanh nghiệp, cơ quan quản lý l). Tổ chức Hội nghị khoa học thường niên về đào tạo và nghiên cứu khoa học trong lĩnh vực môi trường (luân phiên các đơn vị đào tạo chủ trì), qua đó nâng cao năng lực nghiên cứu khoa học, đào tạo, thống nhất thuật ngữ ngành...

- Xây dựng đề án đào tạo bồi dưỡng nguồn nhân lực trình độ cao làm công tác nghiên cứu, giảng dạy về lĩnh vực môi trường. Cán bộ giảng dạy, nghiên cứu cần được tạo nhiều cơ hội đi đào tạo tại các quốc gia có trình độ tiên tiến, tham gia vào nhiều chương trình hợp tác, trao đổi học thuật dự án hợp tác trong nước và quốc tế để từng bước hội nhập sâu, rộng nhằm đáp ứng nguồn nhân lực có trình độ cao cho xã hội.

\section{Kết luận}

Nhân lực là một trong những nhân tố then chốt quyết định, là thước đo quan trọng đánh giá sự phát triển của các quốc gia. Vì vậy, các quốc gia trên thế giới đều rất coi trọng phát triển nguồn nhân lực, mà trong đó nguồn nhân lực trong lĩnh vực môi trường không phải là ngoại lệ, đặc biệt nguồn nhân lực có trình độ cao. Để đáp ứng được nhu cầu và sự phát triển của xã hội, các cơ sở đào tạo cần có những định hướng, kế hoạch cải tiến chất lượng đúng đắn cho nhiệm vụ then chốt này. Cơ quan quản lý cần có các quy hoạch và chính sách phát triển nguồn nhân lực trình độ cao, chất lượng cao, đầu tư kinh phí tương xứng để phát triển, đào tạo nguồn nhân lực về môi trường trong thời đại cách mạng công nghiệp lần thứ tư và đất nước đang bước vào thời kỳ công nghiệp hóa, hiện đại hóa và hội nhập quốc tế. 


\title{
Tài liệu tham khảo
}

1. Nguyễn Mạnh Khải, (2018), Thưc trạng công tác đào tạo và một số tồn tại trong đào tạo nguồn nhân lục ngành Môi truòng, Báo cáo Hội nghị Khoa họ và Đào tạo ngành Môi trường, Trường Đại học Khoa học Tự nhiên, Đại học Quốc gia Hà Nội, Hà Nội.

2. Chính phủ nước CHXHCN Việt Nam (2001), Quyết định số 1363/TTG: QĐ phê duyệt đề án Đua các nội dung bảo vệ môi truờng vào hệ thống giáo dục quốc dân, truy cập: 05/12/2019, $<\mathrm{http}$ //chinhphu.vn/portal/page/portal/chinhphu/hethongvanban?class_id $=1 \&$ _page $=414 \&$ mode $=\mathrm{de}$ tail\&document id $=9868>$.

3. Chính phủ nước CHXHCN Việt Nam (2003), Quyết định số 256/2003/QĐ-TTG: Quyết định phê duyệt chiến lược Bảo vệ môi truờng quốc gia đến năm 2010 và định huớng đến năm 2020, truy cập:

$01 / 12 / 2019$,

$<$ http://vanban.chinhphu.vn/portal/page/portal/chinhphu/hethongvanban?class_id=1\&mode=detail\&document $\mathrm{id}=12424>$.

4. Bộ Giáo dục và Đào tạo (2005), Chỉ thị số 02/2005/CT-BGD\&ĐT: Tăng cương công tác giáo dục bảo vệ môi truoòng, truy cập: 01/12/2019, <https://thuvienphapluat.vn/van-ban/Giao-duc/Chi-thi02-2005-CT-BGDDT-tang-cuong-cong-tac-giao-duc-bao-ve-moi-truong-4819.aspx $>$.

5. Bộ Giáo dục và Đào tạo (2019), Thông tin tuyển sinh 2019. Bộ GD \& ĐT, Hà Nội.

6. Bộ Chính trị (1998), Chỉ thị số 36/1998/CT-TW: Tăng cuờng công tác giáo dục bảo vệ môi truờng trong thời kỳ công nghiệp hóa, hiện đại hóa đất nước, Hà Nội, truy cập: 02/03/2019, $<$ https://thukyluat.vn/vb/chi-thi-36-1998-ct-tw-ve-tang-cuong-cong-tac-bao-ve-moi-truong-trongthoi-ky-cong-nghiep-hoa-hien-dai-hoa-dat-nuoc-b923.html>.

7. Bộ Tài nguyên và Môi trường (2013), Báo cáo hiện trạng môi truoơng quốc gia năm 2013: Môi trường Không khí. Bộ Tài nguyên và Môi trường, Hà Nội.

8. Bộ Tài nguyên và Môi trường (2016), Báo cáo hiện trạng môi truoòng quốc gia giai đoạn 2011 - 2015. Bộ Tài nguyên và Môi trường, Hà Nội.

9. Khoa Môi trường (2019), Giới thiệu Khoa Môi trường, Trường Đại học Khoa học Tụ nhiên, Hà Nội, truy cập: 01/12/2019, <https://fes.hus.vnu.edu.vn>.

10. Ban Chấp hành Trung ương (2004), Nghị quyết số 41-NQ/TW: Về bảo vệ môi truờng trong thời kỳ đẩy mạnh công nghiệp hoá, hiện đại hoá đất nuoóc, Hà Nội, truy cập: 02/03/2019, $<$ http://vbpl.vn/botainguyen/Pages/vbpq-toanvan.aspx?ItemID=74519\&Keyword=>.

\section{ORIENTATIONS ON TRAINING IN ENVIRONMENTAL FIELD OF STUDY TOWARDS THE DEMANDS OF INDUSTRIALIZATION, MODERNIZATION, AND GLOBAL INTEGRATION}

\section{Nguyen Manh Khai ${ }^{{ }^{*}}$, Hoang Anh Le ${ }^{1}$}

${ }^{1}$ Faculty of Environmental Sciences, VNU University of Science, Vietnam National University, Hanoi

\begin{abstract}
Human resource is one of the key factors for the development of any country, in which human resource for the field of environmental protection and environmental quality improvement is not an exception, especially high skilled resources. In order to meet the social needs, training organizations should have appropriate orientation and decisions for this backbone task. Therefore, this article demonstrates the main orientations in improving the training in environmental field of study, in order to provide sufficient human resource for industrialization, modernization, and global integration.
\end{abstract}

Keywords: Human resource, Training, Environmental field, Global integration. 